\title{
Pyrogeography: Understanding the ecological niche of
}

\section{fire}

Max A. Moritz' ${ }^{1}$, M.A. KrawchuK ${ }^{1}$ and M.-A. Parisien ${ }^{1,2}$

'Department of Environmental Science, Policy, and Management Department, University of California, Berkeley, USA; mmoritz@berkeley.edu ${ }^{2}$ Northern Forestry Centre, Canadian Forest Service, Natural Resources Canada, Edmonton

With insights into the controls of past, current and potential future fire patterns, there is great potential to integrate a modern understanding of pyrogeography with paleoecological studies.

Given the impact of fire on ecosystem processes, human well-being and global carbon cycling, there is growing interest in studying fire-environment interactions across various scales of space and time. To this end, the concept of pyrogeographythe study of the distribution of fire-has been put forward as a general framework for evaluating the environmental controls of fire (Krawchuk et al., 2009; Parisien and Moritz, 2009). Pyrogeography, which is inherently spatial, attempts to quantify observed variability in fire activity as a function of the complex interplay of environmental factors. As such, it can be likened to ecological niche concepts that have been applied to species and biological communities. Like biota, fire appears to have an optimal response to environmental gradients and, conversely, tends to avoid its extremes (e.g., deserts, rainforests, tundra).

Environmental factors that generate different fire regimes across the world fall into three basic categories: consum- able resources (vegetation), atmospheric (weather) conditions conducive to combustion, and ignitions (Fig. 1). One method of pyrogeographical research is through spatial distribution modeling, which incorporates mapped fire and biophysical data into a statistical framework. Key strengths of these models include an ability to quantify the contribution of various environmental factors controlling fire's distribution and the use of parameters from statistical models to produce spatially explicit fire activity expected in new regions or under new conditions.

\section{Methodology}

Spatial distribution models describing empirical fire-environment relationships can take many forms and may be estimated using a number of statistical methods. The approach takes advantage of an evergrowing collection of spatial data (e.g., Westerling and Bryant, 2008; Krawchuk and Moritz, 2009; Krawchuk et al., 2009; Parisien and Moritz, 2009). Mapped fire

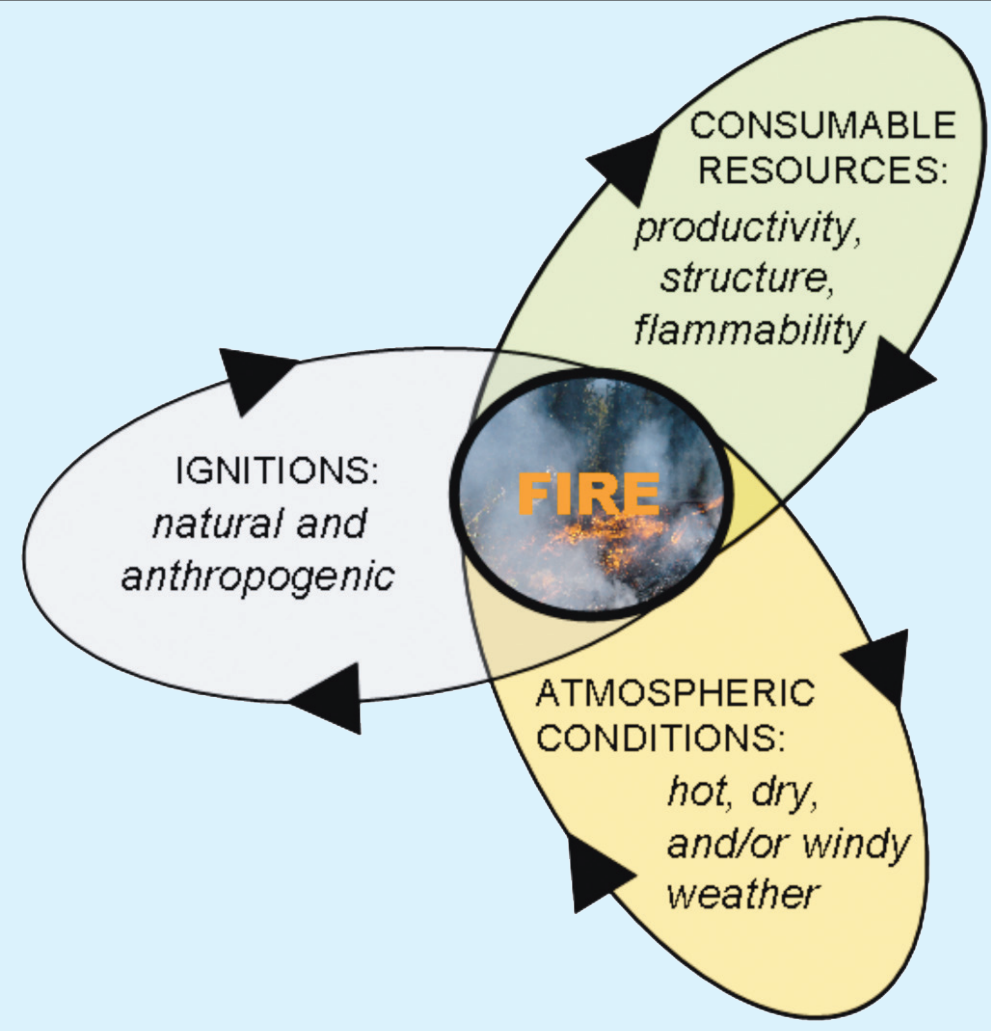

Figure 1: The pyrogeography framework includes vegetation resources to consume, atmospheric conditions, and ignition agents. Each of these components is spatially and temporally variable, as illustrated by arrows, and it is their coincidence that results in fire activity. Variation in their coincidence generates different fire regime types (e.g., frequent low-intensity surface fire versus infrequent high-intensity crown fire). observations (the dependent variable; Fig. 2a) are used in conjunction with spatial environmental gradients (independent variables) to produce statistical models of fire probability (Fig. 2b). Data used to build models and assess hypotheses concerning the distribution of fire can come from many sources, and recent work has shown the importance of variables such as primary productivity, annual precipitation, temperatures in the warmest and/or wettest months of the year, high winds, drought, and monthly soil moisture. The resulting models produce mapped surfaces, as in Figure 2c.

\section{Applications}

Fire distribution models have a host of applications. In climate change science, they have been used to evaluate the current and projected future likelihood of fire at various spatial extents, using projected climate surfaces from global circulation models (e.g., Krawchuk et al., 2009; Westerling and Bryant, 2008). Although the interpretation of future estimates should be evaluated carefully, salient trends may highlight the potential for drastic changes in fire regimes. For example, there is reason to believe that the Tibetan Plateau, a currently fairly cool and moist area, may experience substantial changes in fire likelihood and potentially create a cascade of change (Krawchuk et al., 2009). This is even more worrisome when considering the rapid increase of human access to the area, as a result of infrastructure expansion and population pressures. Accordingly, measurements of uncertainty as a function of differences in projections from these global circulation models (Moritz et al., in review), alongside statistical model uncertainty, are important caveats with such modeling applications.

Fire distribution modeling is also relevant to land management. The technique is currently being used to evaluate largescale land management practices, such as the placement of fuel treatments in the western United States, due to its ability to provide spatially explicit estimates of fire probability. Estimates of current fire probability also offer an opportunity to asses where fire has likely been "extirpated" to 

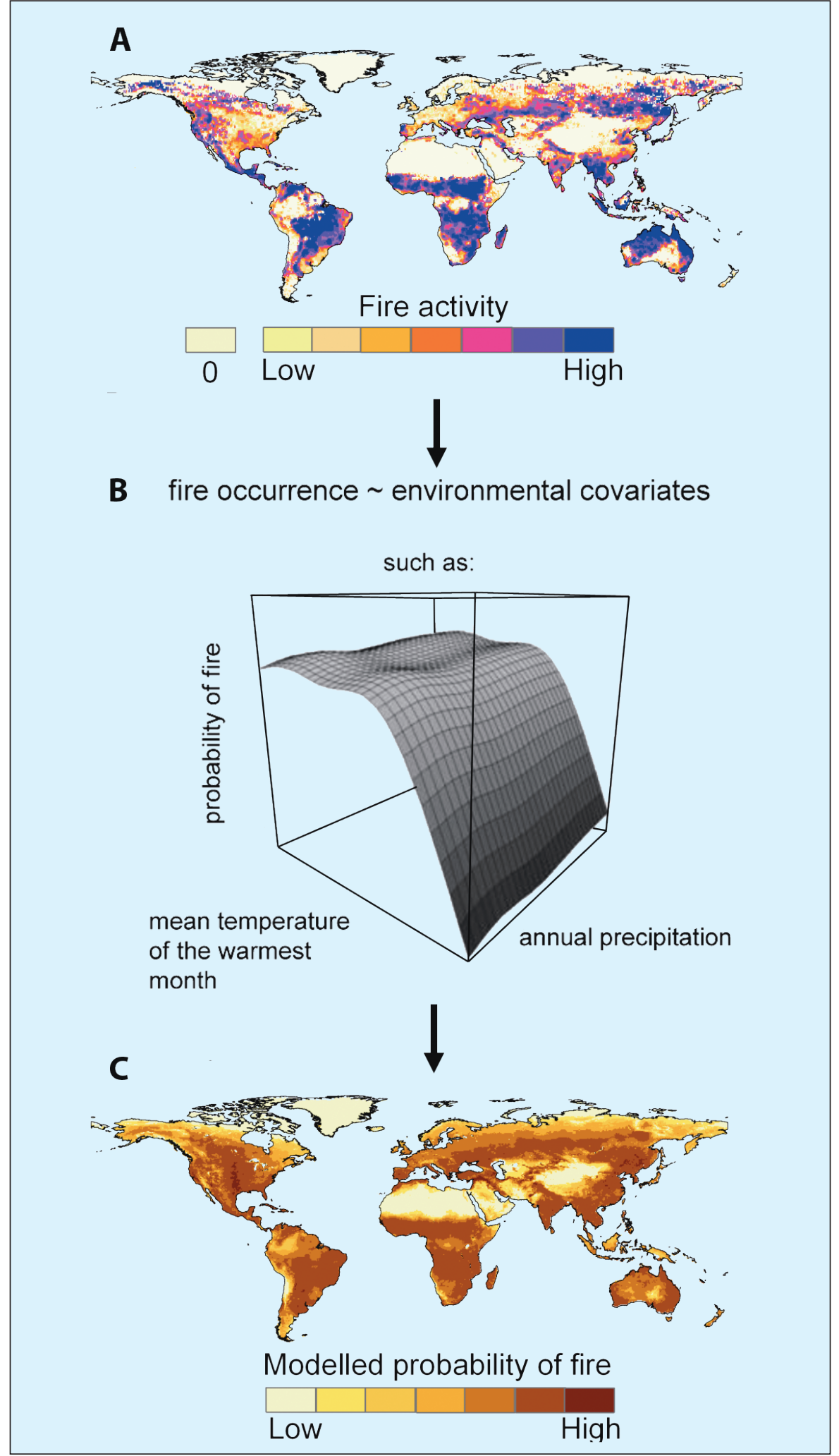

Figure 2:A) Cumulative global fire activity detected by ATSR sensors onboard Earth-orbiting satellites between 1996 and 2006; B) Fire activity is translated to occurrence, then a distribution model relating fire to a suite of environmental covariates representing resources, conditions and ignitions necessary for fire); $\mathbf{C})$ The model is then used to produce a mapped surface demonstrating the modeled probability of fire. Figure based on Krawchuk et al., 2009. inform on-going natural restoration efforts. For example, in the northern Central Valley of California, where fire has been excluded for well over a century because of extensive conversion to agriculture, models suggest that fire may have been fairly frequent given the biophysical space of the region (Parisien and Moritz, 2009).

A key advantage of spatial distribution modeling techniques is their ability to extract relevant information from scarce, the last 200+ years). Krawchuk and Moritz (2009) mapped potential fire regimes in China based on fire-climate relationships and analogues in climate with the United States, a region for which we have a more thorough understanding of fire over recent centuries. These models provide initial estimates of potential fire regimes, yet further studies are needed to help validate these predictions.

\section{Potential integration with paleoecology}

Paleoecological studies based on numerous environmental proxies are providing new insights into relationships between climate and/or dominant vegetation and fire activity over regional and global extents (e.g., Clark, 1990; Millspaugh et al., 2000; Power et al., 2008; Vannière et al., 2008; Conedera et al., 2009; Genries et al., 2009; Higuera et al., 2009; Marlon et al., 2009). Although most of these studies are spatially constrained, they provide empirical records of fire-climate dynamics over longer time horizons than is available through instrumental data records. In a complementary way, the fire distribution models described here provide an excellent opportunity to identify complex relationships between fire and its environmental controls in a spatially complete and coherent manner. Understanding the interplay of controls over recent historical fire activity could thus aid in interpreting fire-environment relationships in paleorecords. An attractive idea for future synthesis of paleofire studies with the fire distribution modeling framework would also be to use back-casted climate data to provide spatial estimates of fire activity under past climatic conditions. Of course, scale issues as well as assumptions about the role of humans (e.g. a source of ignitions) and the couplings between climate and vegetation would need to be carefully incorporated in such an exercise, but the potential for new insights from such studies appears high.

\section{Future outlook}

Environmental changes will cause direct alterations to both vegetation and fire likelihood; however, these two factors are not independent of each other, as changes in one will likely-and sometimes drastically-affect the other. Distribution models of biota could thus be combined with those of fire to paint a clearer picture of fire-climate-vegetation dynamics, which could shed more light on complex feedback mechanisms (Higuera et al., 2009). It could be possible with this approach to map the potential "invasiveness" 
of fire in areas that are undergoing substantial land-use changes or are subject to widespread biological invasions (e.g., cheatgrass in the Great Basin of the United States).

Currently, the spatial distribution models of fire activity described here have primarily been used to explore the occurrence of fires, yet other fire regime elements will be important to include in future work. Fire seasonality, intensity, area burned, and frequency are all elements of a fire regime, and all of these characteris- tics could be expected to shift under past or future climates. Overall, the pyrogeography framework provides a foundation for quantifying the causes and effects of fire regimes, which is critical to understanding fire-related ecosystem function, carbon dynamics and atmospheric chemistry.

\section{References}

Higuera, P., Brubaker, L., Anderson, P., Hu F. and Brown, T., 2009: Vegetation mediated the impacts of postglacial climate change on fire regimes in the south-central Brooks Range, Alaska, Ecological Monographs, 79: 201-219.
Krawchuk, M.A. and Moritz, M.A., 2009: Fire regimes of China: inference from statistical comparison with the United States, Global Ecology and Biogeography, 18: 626-639.

Krawchuk, M.A., Moritz, M.A., Parisien, M.-A., Van Dorn, J. and Hayhoe, K., 2009: Global pyrogeography: the current and future distribution of wildfire, PLOS ONE, 4: e5102.

Parisien, M.-A. and Moritz, M.A., 2009: Environmental controls on the distribution of wildfire at multiple spatial scales, Ecological Monographs, 79: 127-154.

Westerling, A. and Bryant, B., 2008: Climate change and wildfire in California, Climatic Change, 87: 231-249.

For full references please consult:

http://www.pages-igbp.org/products/newsletters/ref2010_2.html

\section{Emerging proxy evidence for coherent failures of the summer monsoons of Asia during the last millennium}

Ashish Sinha ${ }^{1}$ and Max Berkelhammer ${ }^{2}$

'Department of Earth Science, California State University Dominguez Hills, Carson, USA; asinha@csudh.edu

${ }^{2}$ Department of Earth Sciences, University of Southern California, Los Angeles, USA

\section{New high resolution speleothem and tree ring records show evidence for spatially widespread Asian monsoon megadroughts during the last millennium.}

No annually recurring weather phenomena on Earth influence the lives of as many people as the regional summer monsoons of Asia. Agricultural output and consequently food security across Asia is largely dependent on the timely arrival

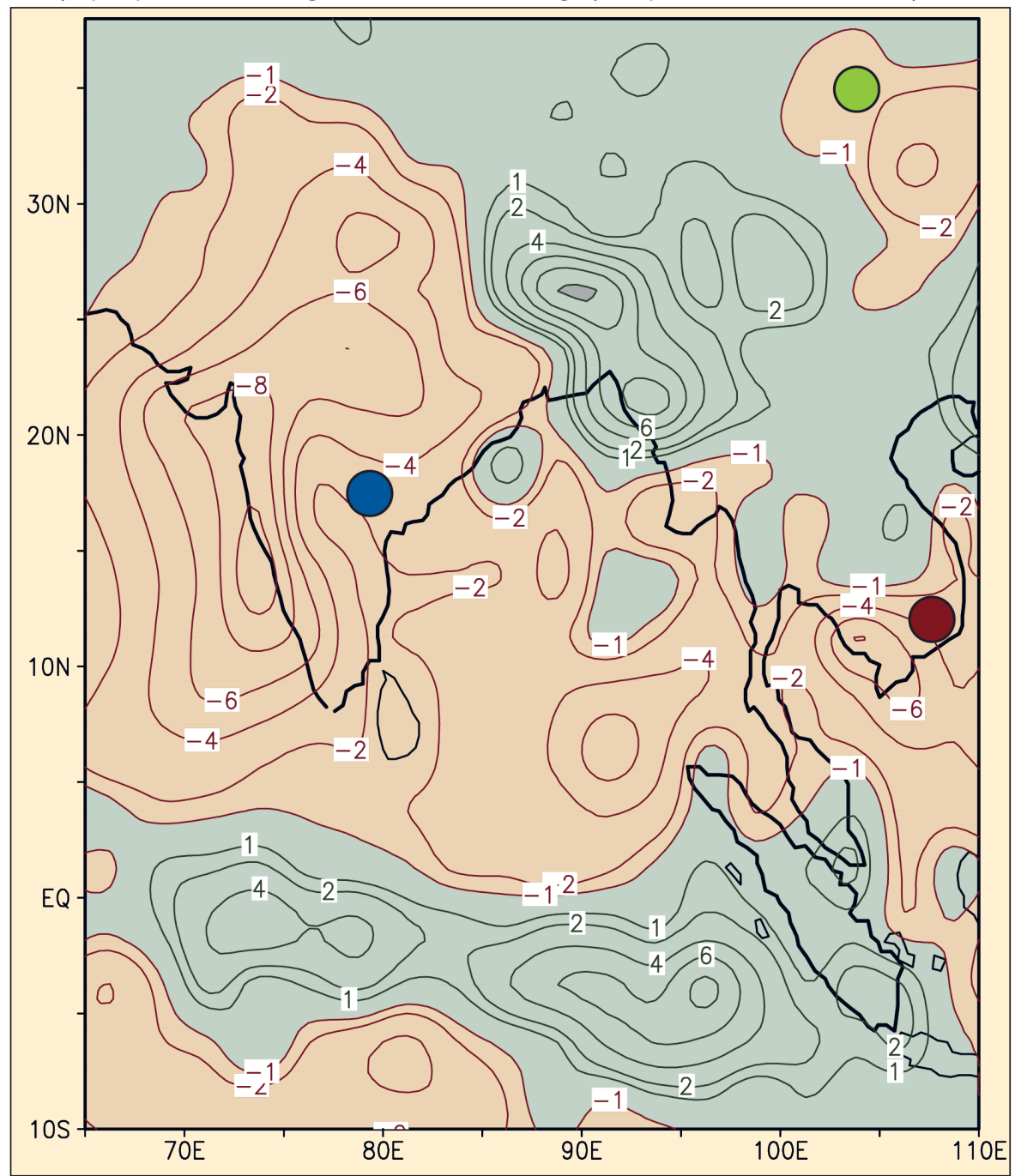

Figure 1: Map showing locations of sites mentioned in the text and Figure 2; Green circle $=$ Wanxiang, blue circle = Dandak, brown circle = Bidoup Nui Ba National Park. Contours and shading indicate July and August precipitation anomalies ( $\mathrm{mm} /$ day) with respect to 1971-2000 interval $(\boldsymbol{r e d}=$ drier, $\boldsymbol{b l u e}=$ wetter) during the major monsoon break spells in 2002 and 2004. Rainfall data are from the Climate Prediction Center Merged Analysis of Precipitation. and adequate amounts of monsoon rainfall. Groundwater resources are often the only safeguard against monsoon failure and their rapid depletion signifies an increased vulnerability to monsoon deviations (Rodell et al., 2009). To a first order, the poleward march of the inter-tropical convergence zone during the boreal summer leads to a large amount of rainfall across the "Monsoon Asia". However, in years when the monsoon circulation and precipitation amount departs from its "normal" spatiotemporal patterns, it can have significant adverse societal impacts. Our current understanding of the variability of the regional summer monsoons of Asia is primarily gleaned from the instrumental record, which is too short to confidently assess the potential end-member hydroclimate scenarios of the monsoon system. Some of the longest instrumental records (starting ca. 1850s $A D$ ) from India show that, barring a few sporadic occurrences of monsoon failure (defined by the Indian Meteorology Department as JJAS rainfall $>20 \%$ below the mean), yearto-year variations in the Indian monsoon rainfall have remained generally within $10 \%$ of its long-term climatological mean. However, historic documentary evidences from the region point to the occurrence of extended spells of substantially reduced monsoon rainfall before the instrumental record began (Maharatna, 1996).

The present day water resource infrastructure and the contingency planning in Monsoon Asia, as informed by instrumental observations, does not take into account the possibility of protracted 